\title{
Android Based Student Data Monitoring System
}

\section{Prerana Deshmukh, Sanskruti Gupta, Ankita Modak, Adarsh Jais, Shraddha Rekhe, Ankush Kure}

Computer Technology, Priyadarshini College of Engineering, Nagpur, India

\section{Email address:}

prerana40484@gmail.com (P. Deshmukh), ankitamodak15@gmail.com (A. Modak),yuvrajjais07@gmail.com (A. Jais), shraddha.15111998@gmail.com (S. Rekhe), sanskrutis.gupta16@gmail.com (S. Gupta), ankush.kure@gmail.com (A. Kure)

\section{To cite this article:}

Prerana Deshmukh, Ankita Modak, Adarsh Jais, Shraddha Rekhe, Ankush Kure, Sanskruti Gupta. Android Based Student Data Monitoring System. International Journal of Intelligent Information Systems. Vol. 9, No. 5, 2020, pp. 56-60. doi: 10.11648/j.ijiis.20200905.12

Received: April 28, 2020; Accepted: May 28, 2020; Published: November 11, 2020

\begin{abstract}
As of late, the Android Technology with web administrations has acquired numerous exceptional changes the versatile application advancement field. This application gives a summed up answer for screen the different works that are done by a College for overseeing it. The framework gives a straightforward interface to support of understudy data. It tends to be utilized by instructive foundations or colleges to keep up the records of students. The creation and the board of precise, state-of-the-art data with respect to a students' scholastic profession is fundamentally significant in the college just as colleges. Well-informed Connect manages all sort of understudy subtleties, scholarly related reports, college subtleties, course subtleties, educational program, batch subtleties, arrangement subtleties and other asset related subtleties as well. It will likewise have faculty subtleties, batch execution subtleties, students' subtleties in all viewpoints, the different scholastic notices to the staff and students refreshed by the college organization. It likewise encourages us investigate all the exercises occurring in the college. Various reports and inquiries can be created dependent on tremendous choices identified with students, batch, course, faculty, exams, semesters, and certification and in any event, for the whole college.
\end{abstract}

Keywords: Android Technology, Administration, Maintain Records, Student Information System

\section{Introduction}

The structure and execution of an extensive understudy data framework and UI are to supplant the present paper records. College Staff can straightforwardly get to all parts of an understudy's scholarly advancement through a protected, online interface inserted in the college's site. The framework uses client validation, showing just data important for a person's obligation. Moreover, each sub-framework has verification permitting approved clients to make or refresh data in that subsystem. All information is altogether assessed and approved on the server before genuine record change happens. Notwithstanding a staff UI, the framework plans for understudy UI, permitting clients to get to data and submit demands on the web, in this way lessening handling time. The Students Data Monitoring System is the android application developed to provide the students of our college with convenience. Our project is a provisional application that will allow the students to access the online portal of our college at a very convenient level. With latest advancements in technology, parents have also become digital and this has further propelled the need to communicate via digital means. With a packed schedule, neither the teachers or administration nor he parents have any time for offline mails and notices. A mobile app is a one stop solution for all the communication solutions. Quick and easy, it's one of the prominent tools in use today. Already, the college depended vigorously on paper records for this activity. While paper records are a conventional method for overseeing understudy information and diverse work, there are a few downsides to this technique. Initially, to pass on data to the students, it ought to be shown on the notification board and the understudy needs to visit the notification board to watch that data. It requires some investment to pass on the data to the understudy. Paper records are hard to oversee and follow. The physical effort required to recover, adjust, and re- document the paper records are all non-esteem included exercises. This framework gives a straightforward interface to the upkeep of understudy data. Instructive organizations or colleges to keep up the records of students effectively very well may utilize it. Accomplishing this goal is troublesome utilizing a manual framework as the data is dissipated, can be repetitive and gathering important data might be very tedious. Every one of 
these issues is unraveled utilizing Smart Connect. The paper centers around showing data in a simple and clear way that gives offices, for example, profile production of understudy, teacher, head, and more significant position authority in this manner diminishing desk work and computerizing the record age process in an instructive organization.

\section{Ease of Use}

\section{Purpose}

The objective of the project is to make it easy for the students to access their data via the app. The app will manage all the student information in the institute. It will provide the centralized control over the system.

Scope

The app is based on students and teachers point of view. The goal is to make it easy for the students to access all the data remotely. Just some clicks and the data will be at fingertips. The basic approach is to use it on all the smart phones. All the students will get accsess to student panel and similarly for teachers and admin.

\section{Litrature Survey}

All researchers have aimed to develop and provide a generalized solution to monitor the various works that are carried out by a College for automation of various tasks. They provided up to date information of the system, which improved efficiency of college record management and decrease the space between student and college. The major contributions to this topic are summarized below:

S. Shivasubramanian, S. Sivasankaran, and S. Thiru Nirai Senthi [1] proposed one of the first computational schemes An Android Based Mobile Application to Monitor Works at Remote Sites. This application provided a generalized solution to monitor the various works that were carried out by a construction company at different geological points. By using a Web Service, the data was stored in the remote database. This mobile application requires General Packet Radio Service (GPRS) or Wi-Fi technology to reach the remote database. Using data in the remote database, various reports were generated and projected as a MIS [Management Information System] web application.

Sanjay T. Attendance [2] proposed attendance Management System to generate an android application to calculate the attendance of the students in colleges and updating the result directly into the college server. The data would be stored in the smart phone if the internet connection were unavailable at that time. When the internet connection was available, then the faculty could login into their college account and update the attendance result.

Shradha S. Chawhan, Mangesh P. Girhale, and Gunjan Mankar [3] worked on MPBAS that helped lecturers to take the attendance of students using Smart-phone. Lecturers would login to the phone application, are connected to the server and take attendance using Smart-phone. After taking the attendance in the mobile, lecturers would send it over to the server using GPRS and attendance list would be updated automatically. Lecturers would be able to edit the attendance by login on to the website. Students would be able to view their own attendance as well as curriculum details. To reduce the chances of fake attendance, the project would include Location detection using GPS. In addition, email would be send to the students by the lecturers, notifying them of their regular activities.

S. R. Bharamagoudar, Geeta, S. G. Totad [4] worked on Web Based Student Information Management System that provided a simple interface for maintenance of student information. Educational institutes or colleges to maintain the records of students easily could use it. The creation and management of accurate, up-to-date information regarding a students' academic career is critically important in the university as well as colleges. Student information system deals with all kind of student details, academic related reports, college details, course details, curriculum, batch details, placement details and other resource related details too.

Eiichiro Tsutsui, Kazuharu Owade, Yusuke Kondo, Michiko Nakano [5] A Proposal For A New- Dimensional Online Feedback System: Focusing On Individual Learner Differences purpose of this study was to create a new method of assessing individual learner differences in the contexts of language learning. Their questionnaire-type items used in that system was based on SILL (Strategy Inventory of Language Learning) questionnaire items.

Namrata Shahade, Priya Kawade and Satish Thombare [6], proposed Student Information Tracking System an Android application to manage student attendance on mobile. In many colleges teachers used to take attendance manually. Main objective of this project is to add mobility and automation in the existing attendance process. This system helps teachers to take attendance through mobile and keep in touch with student in some aspect. This System allow teachers to take attendance, edit attendance, view student's bunks, send important documents in pdf format such as exam time table, question bank etc. and also helps teachers to inform students about the events that college was going to organize. This system also helped students in specifying bunks, deleting bunks, viewing their bunks. This system gives a prior intimation to student as soon as his attendance goes below the specified attendance deadline in the form of an alert. This system helps students to keep in touch with the events that college was organizing.

Yohei Kawaguchi, Tetsuo Shoji, Weijane Lin, Koh Kakusho, Michihiko Minoh proposed a system that took the attendance of students for classroom lecture. Their system took the attendance automatically using face recognition. However, it is difficult to estimate the attendance precisely using each result of face recognition independently because the face detection rate was not sufficiently high. Here they propose a method for estimating the attendance precisely using all the results of face recognition obtained by continuous observation. Continuous observation improves the performance for the estimation of the attendance. They 
constructed the lecture attendance system based on face recognition, and applied the system to classroom lecture.

\section{Problem Defination}

With the advance in time and technology there is a need for faster dissemination of information. The increasing advantages of automated system now are at highest position thus many manual processes are automated. Since the automated system is demanded now-a-days, educational infrastructures like colleges needed their manual system to function on mobile computing systems. Our goal is to create a student data monitoring system using android which can be easily available for the student/teacher in their mobiles.

\section{Approach to the Solution}

Nowadays it is very common to own a smartphone for people, we propose an app that will be easily accessible by student or teachers through their mobile phones anytime anywhere. Changes in Information Technology (IT) allow institutes to utilize databases and applications such as Student Information System thus, making the accessing of records centralized.

\section{Proposed Work}

The Students Data Monitoring System is the android application developed to provide the students of our college with convenience. Our project is a provisional application that will allow the students to access the online portal of our college at a very convenient level. The app will provide each and every piece of information a student would wish to know. We have appended different modules that entail Attendance, Results, Assignments, etc. The students can also access the library information which will entail details about their issued books and returned books, along with other fine related issues.

MODULE:

User Module/Student Module:

In this module we are authenticating the users by providing user name and password.

Database Module:

This module will be used to store all the student related data as well as all the data of the employees working for the institution.

Staff Module:

This module is designed for staff, which use mobile phone to take attendance, upload result and upload college notifications as well as discussion forum.

Notification Module:

This module allows the department HOD to update students about any college related information through notifications.

News and Event Service:

As soon as news about the university/college is released on the university/college website, a notification is sent to all the students and staff.

Assignment and Notes Module:

This service is for both the staff and students, however both have different usage of the feature. Students will be able to view the following information which is critical about the Assignment and Notes; the number of assignments given.

Attendance Module:

This module is for students to keep the track of their attendance. The app will show the real time attendance of the student. Subject wise and overall attendance.

Working:

The Students Data Monitoring System is the android application developed to provide the students of our college with convenience. Our project is a provisional application that will allow the students to access the online portal of our college at a very convenient level. The app will provide each and every piece of information a student would wish to know. We have appended different modules that entail Attendance, Results, Assignments, etc. The students can also access the library information which will entail details about their issued books and returned books, along with other fine related issues. The main objective of this application is to add mobility and automation to the process of managing student information in an institute. The system bridges this gap between the end-users and the contrivance planning managers by providing centralized control over the entire system. Different departments utilize the system for sequencing different processes that are isolated apart.

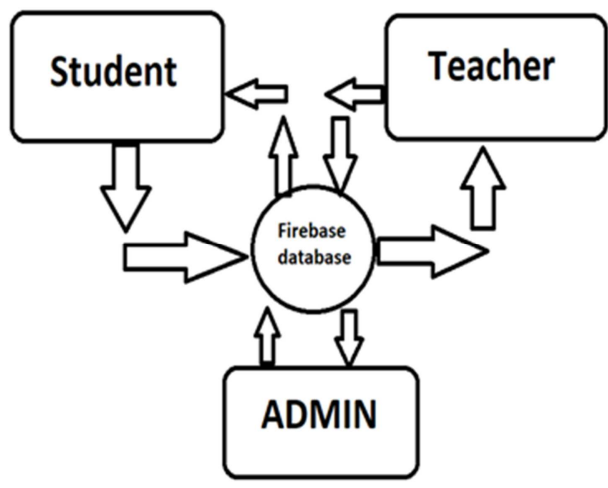

Figure 1. Flow of data from one module to another.

The system design consist of following modules:

Admin login:

The central level authority will be able to login in this portal. The changes can be made in student database through this portal only.

Teacher login:

The teachers will be able to login to this portal for taking attendance, uploading question banks, assignments, marks for the exams, and the basic student information.

Student login:

The students of the institute will be able to login to this portal and can view their personal information and attendance. They will be accessible to the question banks, assignments, notes uploaded by the teacher. 


\section{Software Requirements}

The core function of the project is to create an application to monitor the student data and to provide easy access to that data which uses following software tools:

Windows

Microsoft $\AA$ Windows $\AA$ 7/8/10 (32- or 64-bit)

3 GB RAM minimum, 8 GB RAM recommended; plus 1 GB for the Android Emulator

2 GB of available disk space minimum, 4 GB Recommended (500 MB for IDE + 1.5 GB for Android SDK and emulator system image)

$1280 \times 800$ minimum screen resolution

For accelerated emulator: Intel ${ }^{\circledR}$ processor with support for Intel ${ }^{\circledR}$ VT-x, Intel ${ }^{\circledR}$ EM64T (Intel ${ }^{\circledR}$ 64), and Execute Disable (XD) Bit functionality

Mac

Mac ${ }^{\circledR}$ OS $\mathrm{X} \AA 10.10$ (Yosemite) or higher, up to 10.12 (macOS Sierra)

3 GB RAM minimum, 8 GB RAM recommended; plus 1 GB for the Android Emulator

2 GB of available disk space minimum, 4 GB Recommended (500 MB for IDE + 1.5 GB for Android SDK and emulator system image)

$1280 \times 800$ minimum screen resolution

Linux

GNOME or KDE desktopTested on Ubuntu ${ }^{\circledR} 14.04$ LTS, Trusty Tahr (64-bit distribution capable of running 32-bit applications)

64-bit distribution capable of running 32-bit applications

GNU C Library (glibc) 2.19 or later

3 GB RAM minimum, 8 GB RAM recommended; plus 1 GB for the Android Emulator

2 GB of available disk space minimum, 4 GB Recommended (500 MB for IDE + 1.5 GB for Android SDK and emulator system image)

1280 x 800 minimum screen resolution

For accelerated emulator: Intel ${ }^{\circledR}$ processor with support for Intel ${ }^{\circledR}$ VT-x, Intel ${ }^{\circledR}$ EM64T (Intel ${ }^{\circledR}$ 64), and Execute Disable (XD) Bit functionality, or AMD processor with support for AMD Virtualization ${ }^{\mathrm{TM}}$ (AMD-VTM)

\section{Conclusion}

The system offers reliability, time savings and easy control. Students and their parents will also view results, attendance and curriculum details using this application. Also students can view details, notifications anywhere and anytime. The application will greatly simplify and speed up the result preparation and management process. It provides high security and a system that reduces the work and resources required in traditional process. The proposed system provides the new way of computing and displaying an operations with responsive and attractive user-interface. Thus, on the basis of literature survey and by analyzing the existing system, we have come to a conclusion that the propose system will not only aid the automation to the college, but will also help to digitize the system and in turn help to deploy resources efficiently.

\section{Future Scope}

1. Our Student Management System app usage makes work done at the faster way the software is applicable to view the fee details provided by the administrator of the organization and student can edit his personal details which can be viewed by the administrator.

2. The proposed system is also intended to allow students to view their results on line. This will go a long way to help students decide on what courses to register. The proposed system is intended to manage specific information of students such as personal details, course details and exam details etc.

3. The system will be able to capture, validate, sort, classify, calculate, summarize, store, retrieve, reproduce and communicate operational data. Student Database System will store semester details, course details, department details and all the details of students including their background information, educational qualifications and personal details etc.

4. The system will bring about efficient and effective academic information system. The concise documentation of students and staff details will tremendously improve its timely decision support.

5. The project would also go a long way in fostering good perception of the information age in our various institutions and individual organization thereby breaking the ugly bone of continuous use of manual and archaic systems.

6. It fosters on the in-depth, principles, rules and protocols of coding, scripting and hosting of database driven web pages.

7. It will also help in making the processing of information as well as in the sport feedback faster, enlighten our young database developers and provide for them a springboard. It also stirs and gives focus to our institutions of higher learning on the facilities obtained in the use of modern system of communication.

8. It will accelerate decision making mechanism which will turn the whole system into modern and appreciative.

9. The system will help to reduce the high rate of labor using to its high level of automation and independency.

\section{References}

[1] M. A. Norasiah and A. Norhayati. "Intelligent student information system". 4th International conference on telecommunication technology proceedings, Shah Alam, Malaysia, 0-7803-7773- 7/03 2003 IEEE.

[2] Jin Mei-shan1 Qiu Chang-li 2 Li Jing 3. "The Designment of student information management system based on $\mathrm{B} / \mathrm{S}$ architecture". 978-1- 4577- 1415-3/12 2012 IEEE. 
[3] Zhibing Liu, Huixia Wang, Hui Zan "Design and implementation of student information management system." 2010 International symposium on intelligence information processing and trusted computing. 978-0-7695-4196- 9/10 IEEE.

[4] Donn Felker, "Android Tablet Application Development For Dummies", john Wiley and Sons, 2012.

[5] "Portable Lab: Implementation of Mobile remote laboratory for Android platform", an IEEE paper by Macro Andre Guerra, Claudia Mariline Francisco, RuiNeves Madeira, Portugal.

[6] Krejcar, 0., "PDPT framework - Building information system with wireless connected mobile devices", In Icinco 2006, 3rd International Conference on Infonnatics in Control, Automation and Robotics Instinct Press, Setubal, Portugal, pp. 162-167.

[7] Zigurd Mednieks, Laird Dornin, G. Blake Meike, and Masumi Nakamura, "Programming Android", Second Edition 2009.

[8] Diego Torres Milano,"Android Application Testing Guide", Packt Publishing, 2011.

[9] T. Govindasamy, "Successful implementation of e- learning pedagogical considerations," in The Internet and Higher Education, vol. 4, 2012, pp. 287-299.

[10] D. C. Hillman, D. J. Willis, \& C. N. Gunawardena, "Designing online courses to promote retention," in The American Journal of the Distance Education, vol. 8, No. 2, 1994, pp. 30-42.

[11] K. Akhila, a Novel Approach of Mobile Based Student Attendance Tracking System Using Android Application, International Journal of International Journal of Science,
Engineering and Technology Research (IJSETR), Volume 3, Issue 11, November 2014.

[12] Macro Andre Guerra, Claudia Mariline Francisco, RuiNeves Madeira, Portugal "Portable Lab: Implementation of Mobile remote laboratory for Android platform", an IEEE paper.

[13] Mahfudzah Othman, Zainab Othman \& Mohd. Norafizal A. Aziz, "Student Management System in schools: The use of web-based applications", J. GADING, 10 (1), pp. 87-98, 2006.

[14] Newman-Ford, L. E., Fitzgibbon, K., Llyod, S. \& Thomas, S. L., "A Large-Scale Investigation into the Relationship between Attendance and Attainment: A Study Using an Innovative, Electronic Attendance Monitoring System", Studies in Higher Education, 33 (6), pp. 699-717, 2008.

[15] J. Clerk Maxwell, A Treatise on Electricity and Magnetism, 3rd ed., vol. 2. Oxford: Clarendon, 1892, pp. 68-73.

[16] I. S. Jacobs and C. P. Bean, "Fine particles, thin films and exchange anisotropy," in Magnetism, vol. III, G. T. Rado and H. Suhl, Eds. New York: Academic, 1963, pp. 271-350.

[17] K. Elissa, "Title of paper if known," unpublished.

[18] R. Nicole, "Title of paper with only first word capitalized," J. Name Stand. Abbrev, in press.

[19] Y. Yorozu, M. Hirano, K. Oka, and Y. Tagawa, "Electron spectroscopy studies on magneto-optical media and plastic substrate interface," IEEE Transl. J. Magn. Japan, vol. 2, pp. 740-741, August 1987 [Digests 9th Annual Conf. Magnetics Japan, p. 301, 1982.

[20] M. Young, The Technical Writer's Handbook. Mill Valley, CA: University Science, 1989. 